\title{
'Animals run about the world in all sorts of paths': varieties of indeterminism
}

\section{Jesse M. Mulder ${ }^{1}$ D}

Received: 8 March 2021 / Accepted: 15 July 2021 / Published online: 6 August 2021

(c) The Author(s) 2021

\begin{abstract}
In her seminal essay 'Causality and Determination', Elizabeth Anscombe very decidedly announced that "physical indeterminism" is "indispensable if we are to make anything of the claim to freedom". But it is clear from that same essay that she extends the scope of that claim beyond freedom-she suggests that indeterminism is required already for animal self-movement (a position recently called 'agency incompatibilism' by Helen Steward). Building on Anscombe's conception of causality and (in)determinism, I will suggest that it extends even further: life as such already requires physical indeterminism. Furthermore, I show that we can, on this basis, arrive at the idea of varieties of (in)determinism, along with a corresponding variety of incompatibilist theses. From this Anscombean vantage point, the free will discussion takes on a quite different outlook. The question whether free agency can coexist with determinism on the level of blind physical forces, which preoccupies the philosopher of free will, turns out to conflate a whole series of compatibility questions: not just whether life is compatible with physical determinism, but also whether animal self-movement is compatible with 'biological determinism', and whether free agency is compatible with 'animal determinism'.
\end{abstract}

Keywords Indeterminism · Incompatibilism · Causality · Determination · Free will · Anscombe

This article belongs to the topical collection "Causality and Determination, Powers and Agency: Anscombean Perspectives”, edited by Jesse M. Mulder, Dawa Ometto, Niels van Miltenburg, and Thomas Müller.

Jesse M. Mulder

j.m.mulder@uu.nl

1 Department of Philosophy and Religious Studies, Utrecht University, Janskerkhof 13,

3512BL Utrecht, The Netherlands 


\section{Anscombe's libertarianism}

Towards the end of her inaugural lecture at Cambridge, entitled 'Causality and Determination', Elizabeth Anscombe decidedly and unambiguously declares herself a libertarian regarding free will:

My actions are mostly physical movements; if these physical movements are physically predetermined by processes which I do not control, then my freedom is perfectly illusory. The truth of physical indeterminism is thus indispensable if we are to make anything of the claim to freedom. (C\&D: 146) ${ }^{1}$

This remark gives voice to a quite fundamental anti-compatibilist intuition, which is well-known in the shape of, e.g., Peter van Inwagen's 'Consequence Argument' and Derk Pereboom's 'Manipulation Argument'. ${ }^{2}$ Anscombe made the remark as an afterthought in a lecture which, in its main parts, is not at all directly concerned with freedom or intentional agency, but rather with, indeed, the far more general notions of causality and determination. ${ }^{3}$ It will be my aim in this essay to bring out how her views on the latter may be used to develop 'varieties of indeterminism', an idea that helpfully illuminates our very understanding of the free will problematic.

Anscombe comes to express her libertarianism in response to the "severe criticism" that "this "mere hap""-physical indeterminism-"is the very last thing to be invoked as the physical correlate of 'man's ethical behaviour"' (C\&D: 145). And this, in turn, expresses a fundamental anti-incompatibilist thought; the one underlying the much-discussed 'Luck Objection'. ${ }^{4}$ She confidently takes the sting out of that criticism (at least partly) by noting that " $[\mathrm{t}]$ he physically undetermined is not thereby "free",; freedom is "not to be analysed as the same thing as, or as produced by, the physical haphazard" (C\&D: 146). Nevertheless, she insists that

there is nothing unacceptable about the idea that that 'physical haphazard' should be the only physical correlate of human freedom of action; and perhaps also of the voluntariness and intentionalness in the conduct of other animals which we do not call 'free'. (C\&D: 146; my emphasis).

Clearly, Anscombe was envisaging a form of libertarianism on which 'physical' indeterminism is a necessary ingredient in setting the stage on which we humans can act freely, but no part of the positive conception of free agency. On that point,

\footnotetext{
1 All references to 'C\&D' are to Anscombe (1971).

2 See van Inwagen (1975, 1983) and Pereboom (2001: Ch. 4; 2014: Ch. 4).

3 Van Inwagen mentions Anscombe's inaugural lecture as one of two "works that have influenced [him] as regards special but important points" (Inwagen 1983: vi). Later in his book (cf. pp. 4, 139) it becomes apparent that the 'special point' in question is her dissociation of necessity from causation. I return to this below. Pereboom (2001: 43n12), too, refers to this particular Anscombean thought.

4 Though he rejected the Luck Objection, which he then called the Mind Argument, in his (1983: p. 128-9), van Inwagen later came to endorse a variant called the Replay Argument (see van Inwagen 2000). For a discussion of the luck objection that is Anscombean in spirit, and thus aligns well with the present paper, see van Miltenburg and Ometto (2019).
} 
she offers only the very brief remark that it involves "the power of acting according to an idea" (C\&D: 146). ${ }^{5}$

Moreover, she apparently holds that a similarly-structured view is apt regarding animal behavior at large. This resonates with Helen Steward's (2012a,b) 'agency incompatibilism', on which it is not the narrower idea of morally responsible, free agency, but rather agency as such which requires indeterminism, where 'agency' is understood to extend significantly into the domain of animal self-movement. Now, this seemingly casual broadening of scope in Anscombe's paper is, as we will see, not casual at all; in fact, it follows quite naturally from the conception of causality developed in C\&D.

Further reflection on the picture we can thus extract from Anscombe's work reveals the need for an understanding of the idea of incompatibilism (the requirement of indeterminism) that is much more differentiated than what we find in most of the contemporary literature on agency and free will. Consequently, I will argue, we need to distinguish different 'varieties of indeterminism', and a corresponding variety of incompatibility claims. In effect, these varieties distinguish 'levels' within the natural world, 'levels' which are related in such a way that each 'higher' level requires indeterminism on the 'lower' level(s). Drawing on Anscombe's reflections, I will be working with a provisionary list of such levels in this paper: free agency ('acting according to an idea'), animal behavior, life, the 'physical haphazard'. But it is not this specific list of levels that I aim to be developing and defending here; rather, it is the very idea of such levels, differentiated by varieties of indeterminism and incompatibilism, that I aim to get into focus.

Hence my primary aim in what follows is to bring out this broader, differentiated incompatibilist picture, highlighting along the way the transformed shape that the traditional free will problematic takes on once we put it in this Anscombean light. More specifically, when we position Anscombe's libertarianism against the background of the overall understanding of causality and determination she develops, we can come to see (1) that the requirement of indeterminism does not spring from freedom specifically; (2) that it springs from her understanding of causality as, primarily, a 'local' matter of interacting substances; and (3) that this understanding invites a metaphysical picture that makes room for diverse 'levels'.

Let us, therefore, first have a closer look at what Anscombe exactly has to say on causality.-It should perhaps be kept in mind that I will not undertake to properly defend the Anscombean picture that I develop below; my aim is merely to sketch it in order then to show how it gives rise to the promised varieties of indeterminism and the ensuing reshaping of the classical free will debate.

\footnotetext{
5 With this mere hint, Anscombe is clearly referring to her action-theoretic reflections in her monograph Intention (Anscombe 1957). She there approaches the topic of intentional action through the famous question 'Why?'. Note that this question (when taken in a different, broader, 'sense') can also be read as the defining question for the topic of causality more broadly. Compare the opening pages of Anscombe (1983).
} 


\section{Anscombe on causality}

Anscombe's self-declared aim in C\&D is to reject the habit of associating the idea of causation with necessity and/or universality. Eventually, she isolates the "core, the common feature, of causality", which thus doesn't involve the ideas of necessity or exceptionless generality, as follows: "causality consists in the derivativeness of an effect from its causes ... Effects derive from, arise out of, come of, their causes" (C\&D: 136).

Moreover, she adds that "analysis in terms of necessity or universality does not tell us of this derivedness of the effect; rather it forgets about that" (C\&D: 136). The reason is, in a nutshell, that, although both necessity and universality may be in play in a (or any) given case of causality, this will then be an additional fact, one which places the causal happening here and now in the context of some natural law or true universal generalization. However, while focusing on such an additional fact, we lose sight of the original fact of the causality here and now. ${ }^{6}$

Given that Anscombe thus expels the elements of necessity and universality from our conception of causality, it is only natural that she has been claimed as one of the leading advocates of 'singularism', the view that, as Ann Whittle puts it:

Causal connections between two relata [don't] depend upon anything extraneous to that relation. Rather, the truthmakers of singular causal statements are entities which are local and intrinsic to those relations. (Whittle 2003: p. 372)

And this impression is reinforced when we read, e.g., Anscombe's eventual definition of 'necessitating cause' (on which more below): "a cause $C$ is a necessitating cause of an effect $E$ when (I mean: on the occasions when) if $C$ occurs it is certain to cause $E$ unless something prevents it" (C\&D: 144). Anscombe puts very much emphasis indeed on the fact that this definition is to be read as regarding particular 'occasions', and not as introducing a general link that holds between all instances of $C$ and $E$.

Another metaphysician who appeals to 'singular causation', with reference to Anscombe, is David Armstrong. Indeed, he is so convinced of Anscombe's 'extreme' singularism that he writes: "in opposition to those such as Anscombe (1971) for whom causation is essentially singular, singular causation is not ontologically primitive. It can be given an ontological analysis ... as the instantiation of a law of nature" (Armstrong 1997: p. 202).

However, as Ometto (ms.) convincingly argues, it is not necessary to associate Anscombe with singularism in this manner. For, arguably, Anscombe actually believes that there is a general element relevant to causality. She just rejects the notion that this generality takes the shape of necessity or universality (which appear

\footnotetext{
${ }^{6}$ Of course, ever since Hume philosophers have been skeptical of such 'original facts' of causality. Anscombe gives short shrift to such skepticism (C\&D: 137-8). Barry Stroud offers a much more developed rendering of the anti-Humean line of thought that Anscombe merely hints towards in his very rewarding chapter on causality (Stroud 2011: Ch. 2; esp. pp. 23ff). See also Mulder (2018b).
} 
to be the only forms of generality Armstrong could think of ${ }^{7}$ ). Rather, the generality involved is a broadly Aristotelian one, relating to powers possessed by natural kinds. Here is her most explicit statement on the matter:

Suppose we were to call propositions giving the properties of substances "laws of nature". Then there will be a law of nature running "The flashpoint of such a substance is. . ", and this will be important in explaining why striking matches usually causes them to light. This law of nature has not the form of a generalization running "Always, if a sample of such a substance is raised to such a temperature, it ignites"; nor is it equivalent to such a generalization, but rather to: "If a sample of such a substance is raised to such a temperature and doesn't ignite, there must be a cause of its not doing so." (C\&D: 138)

There isn't much by way of elucidation of this conception of natural laws in C\&D. ${ }^{8}$ And although much more would need to be said on the peculiar generality present in such Anscombean laws of nature-i.e., in powers-that is not the topic of this paper. ${ }^{9}$

What matters for present purposes is the resulting shift in our understanding of what it is for something to happen as such. In an unduly neglected paper in defense of a 'limited indeterminism', Arthur Prior once characterized this understanding as follows:

[T] he world consists not of events, such as headaches, but of things, such as heads, which act and interact and change. ... [H]ow things behave-that is, what events occur-is determined partly by their natures or dispositions, and partly by what happens to them. (Prior 1962: p. 58-9)

What happens is determined, in part, by the 'natures or dispositions' of the things that happen to be around: this nicely captures the general metaphysical orientation that is present in the background of Anscombe's lecture. ${ }^{10}$ Against this background, it is much easier to understand her otherwise rather obscure definitions of necessitating and non-necessitating causes, and of determinism and indeterminism. Let us start with the former:

[A] necessitating cause $C$ of a given kind of effect $E$ is such that it is not possible (on the occasion) that $C$ should occur and should not cause an $E$, given that there is nothing that prevents an $E$ from occurring. ${ }^{11}$ A non-necessitating cause is then one that can fail of its effect without the intervention of anything to frustrate it. (C\&D: 144)

\footnotetext{
7 See Mulder (2021a,b) for elaboration.

8 There is, of course, her famous chess analogy, further down, where "the play is seldom determined, though nobody breaks the rules" (C\&D: 143) — the rules here being quite accurately describable as including the 'powers' of the chess pieces within the game.

9 But see Ometto (ms.) for more; and see also Mulder (2021a, b).

${ }^{10}$ This way of understanding 'what happens' in relation to laws of nature is clearly closely akin to Nancy Cartwright's (1983) conception of 'how the laws of physics lie'. See in particular also Cartwright and Pemberton (2013).

11 Anscombe gives two versions of her definition of necessitating cause, one in terms of certainty, and then, because this may seem too epistemic, she adds the other one, in terms of possibility. Earlier I quoted the first, this is the second.
} 
It may strike one as odd, that Anscombe leaves open the possibility of prevention in her definition of necessitating cause. How can a necessitating cause ever be thwarted? The contrast with the non-necessitating cause helps to clarify what is meant. Suppose, to take a less destructive variant of an example Anscombe takes from Feynman (C\&D: 144-5), that you put some radioactive material in the vicinity of a Geiger counter, intending to thereby make it register a certain reading. Depending on the specifics of the case, it may very well be that all is set for the desired reading to be registered-and yet it doesn't. Nothing interferes with the process of decay (we imagine that there is radioactive decay going on, just not enough to trigger the relevant reading); it is just that this is a case of 'non-necessitating' causality. By contrast, if you drop a stick in mid-air, it will fall to the ground-unless, indeed, something prevents it. Your dog, for instance, might jump up and catch the stick in mid-air. But it is impossible that the stick should simply hang in the air where you left it of its own accord. Gravity, the power of massive objects to attract each other, acts as a necessitating cause. But whether it will actually result in the corresponding change of position depends not just on the 'laws of gravity' but on the specifics of the situation at hand-on the 'natures or dispositions' of the substances that happen to be around. The presence of dogs makes a difference (although the difference it makes is itself not likely to be necessitating).

Now suppose the thing you are dropping is not a stick, but rather a chicken of exactly the same weight. Neglecting differences in the way air resistance affects stick-shaped and chicken-shaped physical objects, the laws of gravity will indicate an identical outcome. But there is more to the chicken than its weight: it can fly, and may very well start doing so upon being released in mid-air. (And, again, your dog might interfere as well.)

This should suffice to illustrate how Anscombe thinks of laws and causes. If we think of the world as fundamentally inhabited by interacting things in this way, then these things include not just the particles of physics or the stuffs of chemistry, but also dogs and chickens and people. And these have powers-such as the power to fly, or the power to act according to an idea-that are completely different from any of the powers possessed by physical particles or chemical stuffs. Yet, as our examples indicate, these powers may interfere with the manifestation of physical or chemical powers. On this basis we can see why Anscombe ends her essay with the remark: "The most neglected of the key topics in this subject are: interference and prevention" (C\&D: 147).

\section{Anscombe on indeterminism}

There is nothing objectionable about things interfering with exercises of the power of gravity. In fact, gravity itself can be thought of as 'interfering' with gravity: the relative movements towards each other of two heavy objects, as dictated by the laws of gravity, will not materialize if a third heavy object is present in the vicinity. The point is quite trivial once we have shed the tendency to think of causes in terms of necessity or universality: what will actually happen is not determined by the laws of any specific feature or power or force, for there may always be other things present 
with additional features or powers or forces. Abstractly speaking, then, interference with the power of gravity by a playful dog is no different from interference by another heavy object.

But there is a difficulty when we look more concretely at such a situation. For the dog itself is composed of physical particles and chemical stuffs-and these particles and stuffs presumably behave in accordance with their nature, whether they're inside the dog or not. So how can the dog as a whole make any difference to what its constituent matter is doing?

We must distinguish between two senses of this question. Borrowing Jonathan Lear's apt distinction: we can put the question either 'with a skeptical sneer' or rather 'with a straight face' (see Lear 1984). To answer the latter question, which is a genuine inquiry into how there could be such a difference-making on the part of the dog, we need to distinguish matter from material. The matter inside the dog isn't just matter, for the dog uses it as material. ${ }^{12}$ More concretely: if the dog is to interfere, out of its playful desire, with the falling stick, then that desire must be effective in steering the dog's constituent matter accordingly. This in turn means that the constituent matter must leave open a range of physical outcomes, which partly constitute the behavioral options open to the dog, to be narrowed down further by the dog's desires, impulses, and instincts. In this way, then, the dog can make a difference to what its constituent matter does, without of course ever breaking the laws governing that matter. ${ }^{13}$

I will elaborate on this answer to the 'straight face' question shortly. But, although this lies strictly outside of the concerns of this paper, let me briefly touch upon the 'skeptical sneer' version of that question as well. It can, for instance, take the following shape: by which mechanism does the dog exert influence on its constituent matter? This question is then not to be answered by merely pointing out that the dog uses the 'mechanisms' of his muscular system, for instance. What the mechanistic inquiry is after is, rather, a mechanism by which the dog makes its constituent matter (including its muscles) do things that that matter would not be doing 'on its own' in the first place. And obviously, the mechanistic inquiry isn't particularly interested in dogs; it wants to know how substances generally can exercise powers of their own by 'using' their materials.

Put in this way, there will be no satisfactory answer-and the reason why there will be no such answer is precisely because it rests on a 'skeptical sneer' towards the Anscombean-Priorian conception of interacting substances as such. Compare a

\footnotetext{
${ }^{12}$ An anonymous referee helpfully pointed out to me that this statement requires qualification. There may be matter 'inside' the dog that is not, and cannot, be used as material in the relevant sense- - suppose, e.g., that the dog has swallowed a small rock. Furthermore, it looks like we need to make a difference between the 'using of material' that is purely biological, like the way in which the dog's digestive system takes up nutritive substances, and the agentive 'using of material' that is relevant to my example here, which consists in the dog's moving its body in accordance with its perceptions and desires. This further differentiation foreshadows the 'varieties of indeterminism' I aim to get into view in what follows.

${ }^{13}$ Not that it is left completely open what can happen: the laws governing that matter will constrain the possibilities greatly. That is, by the way, why Prior named his view "limited indeterminism."
} 
similar mechanistic inquiry in the case of the matter itself: electrons, being negatively charged, repel each other-but by what mechanism do they exert such influence? We must say: by no mechanism; rather, it is through having the power of electric charge (among other powers) that electrons can be invoked in mechanistic explanations in the first place. ${ }^{14}$ In short: the categories of substance and power are basic; it is in terms of interacting substances that we can understand what goes on. But this is, to repeat, a highly abstract insight; nothing in the very idea of substance and power prohibits there being composite substances. A dog is such a substance, with powers of its own; these are, on our present picture, metaphysically as well as explanatorily basic. ${ }^{15}$ Of course, much can be said concerning the way in which a dog exercises its 'agentive' powers (e.g., by using its muscular system in certain ways), but that more detailed story concerning the dog's agency will simply take its place within the fundamental, metaphysical conception of it as a substance having certain powers. It will answer our straight-face question for the particular case of the dog, not the skeptical-sneer question.

So much for our brief excursus. Notice that we have finally returned, now, to the casual broadening of the requirement of indeterminism from free agency to animal behavior registered in $\S 1$ above. Here is another quote to the same effect taken directly from Anscombe's discussion of causality:

We could say: of course nothing violates ... the laws of the force of gravity. But animals, for example, run about the world in all sorts of paths and no path is dictated for them by those laws .... (C\&D: 143; my emphasis)

Again, it is not animals per se that Anscombe seems to be interested in ('for example', she writes). Rather, her essay as a whole points towards a more general conclusion: that, on a metaphysical picture of interacting substances, the requirement of physical indeterminism arises as soon as we want to acknowledge substances that have the power to do certain things by using their constituent matter in certain ways-in short, where matter is used as material. And it looks like this is paradigmatically true not just for free agency, and not just for animal behavior either, but for the realm of the living at large. ${ }^{16}$

\footnotetext{
${ }^{14}$ Of course, there may be further, more advanced scientific insights into the specifics of interactions between electrons, yet it is clear that, as long as we stick to the substance-power scheme, at the ultimate 'bottom-out' point we will still find certain substances with certain powers.

15 Here the skeptical sneer may take on a different shape: it is fine to have fundamental particles which are 'basic' in the sense described, but surely dogs aren't 'basic' in this sense? Aren't they mere products of evolution, 'derivative' rather than 'basic' beings? I cannot discuss this vexed reductionist objection in detail here (but see Mulder (2016, 2021c)); yet, for what it is worth, here is one pertinent consideration: this objection threatens to confuse two senses of being 'basic': a metaphysical and a mereological (or perhaps rather aetiological or ontogenetical) one. The metaphysical category of substance doesn't rule out composite, evolved substances, and so it is perfectly possible that there be metaphysically basic substances which are nevertheless physically composite and biologically evolved.

16 I have argued for such a 'vitalist' incompatibilist claim at length in Mulder (2016, 2021a). Perhaps, the claim must be extended even further, to all composite objects, alive or not. See, e.g., Elder (2011) for such a stance.
} 
Thus we arrive at an incompatibility claim of much broader scope that the one usually found among libertarians in the free will debate. However, that doesn't yet give us the promised varieties of indeterminism and incompatibility. Before we move on to develop those (in $\$ 4$ below), we need a better grasp on what it means, exactly, to endorse indeterminism, on our Anscombean picture. She herself defines it as follows:

I should explain indeterminism as the thesis that not all physical effects are necessitated by their causes. (C\&D: 145)

Conversely, then, determinism will be the thesis that all physical effects are necessitated by their causes. That still doesn't mean that nothing can interfere with any given case of necessitating causation: it just means that that interference itself then must be the result of a necessitating cause as well. (For instance, a billiard ball's movement towards the pocket may be interrupted by another ball, which got its momentum from a fine hit by a player's cue, which is a necessitating cause of movement.) Given the background metaphysical picture of interacting substances, it is always in principle possible that something interferes with a given necessitating cause. But if all that happens involves necessitating causes, then nothing outside of the actual unfolding of events is possible.

Or, at least, that seems to be what Anscombe has in mind when she defines indeterminism in this way. There is, however, a complicating factor: nothing in Anscombe's definition of 'necessitating cause' prohibits there being necessitating causes the effects of which aren't fully determinate. Take her own example of rabies being a necessitating cause of death (you're sure to die from it without treatment ${ }^{17}$ ): the rabies doesn't necessitate exactly when, where and how you're going to die from it-not in every conceivable detail. Thus it may well be that "all physical effects are necessitated by their causes" without it being the case that the future course of events is fully predetermined-i.e., without determinism being true. ${ }^{18}$

In fact, I think this observation adds to Anscombe's case for her thesis that "[i] $t$ is the [determinist's claim of] total coverage of every motion that happens, that is a fanciful claim"-which is why she insists that "indeterministic physics ... is only culturally, not logically, required to make the deterministic picture doubtful" (C\&D: 147). ${ }^{19}$ After all, if necessitating causes indeed leave room for a certain range of outcomes (all of which conform to that which is necessitated, of course), then this may be thought to already provide for the leeway I claimed to be required by the vital operations of living beings, the behavior of animals, and the free actions of thinking beings like ourselves.

\footnotetext{
17 Well, not really - there turn out to be few but significant exceptions. See Gilbert et al. (2012).

18 It may be thought that this complication arises only because we specify the cause too generically: generally speaking (at the type level), it may well be true that rabies doesn't settle the relevant details, but what about this specific instance of it (at the token level); might there not be full coverage of the relevant details there?-To see why this is no option for Anscombe, recall our discussion of 'causal singularism' earlier.

19 In a later paper, she speaks in this connection of a "deterministic itch" (Anscombe 1983: 105).
} 
And indeed, many of the typical arguments and examples one finds in Anscombe's essay are intended to show that even if we take the relevant goings-on to be the result of necessitating causes only, still there is no way in which we can conclude that the end result was predetermined (see, for instance, her discussion of the bouncing balls; C\&D: 142).

But I do not think Anscombe is entirely clear on this matter in C\&D. On the one hand, it looks like her definition of indeterminism, as well as her short discussion of the import of indeterministic physics with regards to the free will problem, assume that unless we have non-necessitating causes, determinism is true. On the other hand, as I just indicated, her overall strategy is one of dissociating the 'fanciful claim' of determinism even from the notion of deterministic laws (i.e., laws governing necessitating causes).

We can amend the situation for Anscombe in two ways. At first sight, it may seem that we should simply redefine 'necessitating cause' so that it only applies to cases where what is necessitated is determinate in every respect. But it is quite doubtful whether there will then be any necessitating causes. (Briefly put, these would then either have to be governed by laws so precise that they exceed limits of accuracy beyond which we cannot really give meaning to their statements ${ }^{20}$, or they would collapse to singular (token) causes, which we discussed earlier.) It thus doesn't look like this solution sits well with Anscombe's philosophical outlook.

The alternative is to redefine 'indeterminism' more specifically as the claim that not every physical effect is predetermined in every respect. Given Anscombe's preference for the term '(un)predetermined' throughout the lecture (a notion she does not explicitly define), this looks to be the better solution. And it also fits better into the basic metaphysical framework of substance and power against which I have been plotting her considerations. Recall that, on that conception, powers embody the element of generality, which Anscombe regains by rejecting the involvement of universality and necessity in the very concept of causality. Powers point towards their manifestation, we could say, but this 'pointing' is not a matter of relating the given, particular situation to a particular manifestation-situation later on. Rather, powers point to their manifestations generically (e.g., rabies leads to death), and such a generic manifestation can materialize in many particular ways. ${ }^{21}$ Thus understood, it becomes clear why determinism would be a 'fanciful claim' even if one insisted that there are only ever necessitating causes.

Now that we have sketched out Anscombe's conception of causality and (in) determinism, let us return to our strong incompatibilist claim and see how it gives rise to varieties of indeterminism and incompatibilism.

\footnotetext{
${ }^{20}$ Compare Anscombe's discussion of the "finite accuracy of measurements" and the obvious limits to their refinement once we get to (or beyond) the scope of the subatomic particles (C\&D:139-40).

${ }^{21}$ For more on this conception of powers, see Mulder (2021a, b).
} 


\section{Varieties of indeterminism}

My rough sketch of Anscombe's take on causality and indeterminism was meant to reveal the point at which indeterminism becomes a requirement for her. We saw that this point lies wherever something has powers that are exercised by making use of the possibilities offered by its constituent matter. I said that things having such powers are not their matter but rather have matter, which then is their material. ${ }^{22}$ Now, in general, wherever matter is used as material for some substance or activity $X, X$ must be allowed by the laws governing that matter, even though it will not spring from those laws. More concretely, I endeavored to claim that this point lies not where human free agency starts, but is to be located much lower on the scala naturae, namely where life starts.

The following comparison may help to see how the relations between matter, material, indeterminism, and determination lie, on our Anscombean picture. Consider the physical matter that composes your house: it allows for the physical configuration it in fact takes on in your house-it allows to be used as material for that purpose-but it doesn't organize itself in that way of its own accord. Rather, the cause of its actually taking on that organization lies in the realm of human agency-houses are, after all, paradigmatically organized in accordance with an idea.

Now it may seem that these two accounts of the origination of your house-in human agency, or rather in the sum of the physical processes leading up to itare rival accounts. In her later essay 'The Causation of Action' (1983), Anscombe reflects on that suggestion in the context of a longer discussion of the question how human action comes about (and here, too, she extends the discussion at points to include animal behavior as well). She discusses the broadly physiological project of tracing out the "causal history" of an action: e.g., tracing back the action of pushing a door open via the muscles and efferent nerves to the afferent nerves and the eardrums via which certain vocal sounds (the order to do so) were transmitted. And she contrasts such a causal history with one of "a different type from the physiological one" (Anscombe 1983: p. 100): one involving beliefs, desires, intentions, orders, etc. Her point eventually is that "The causal histories of the two types aren't rival accounts" (Anscombe 1983: p. 101). And this is just what we should say about the house example. For one can describe what went on, purely physically speaking, with all the little bits of matter that ended up composing your house. This purely 'physiological' causal history of the house will not mention the beliefs, desires, intentions, etc. of human beings. It will, rather, simply mention a wide range of consecutive physical processes and forces-forces by which, we can say, employing the other, intention-involving 'causal history', the various building materials were assembled according to some plan, and finally put together to result in your house. Again, the

\footnotetext{
${ }^{22}$ Helen Steward in this context aptly speaks of animals as 'having' rather than 'being' their bodies. She writes, for instance, that: "The distinction between things which 'have' bodies and things which do not, indeed, has a good claim to be simply identical with the distinction between agents and non-agents" (Steward 2012b: p. 246).
} 
two accounts aren't rivals. ${ }^{23}$ We make clever use of in-principle available physical goings-on for our project of building houses.

Now, interestingly, these considerations point to a more fine-grained differentiation of levels than just the dual one of matter and what it is used for by that to which it stands as material. To see how, notice first that the causal history of your house is badly characterized as 'physiological': it is really a physical causal history. The physiological account of what goes on in a human organism when an action is performed, by contrast, is best understood as a biological account, as opposed to an exclusively physical account. It speaks of things like muscles and nerves, after all.

It follows that it is not sufficient to speak of two levels. We do not merely have a general contrast of physical matter and what it is used by as material-e.g., a plant, or a dog, or a human being-but we must acknowledge a further contrast of biological, living tissue and what it is used for. Accordingly, a dog's body, let us say, considered just as a living organism, on the one hand uses inanimate, physical matter as material (and thus requires indeterminism on the level of inanimate matter), but on the other hand, it provides the basis for the dog's animal agency, which in turn requires indeterminism on the biological level. ${ }^{24}$

Such a biological indeterminism can be thought of as follows: the dog's body is constantly regenerating itself, keeping itself alive, and while doing so it enables a certain range of possible movements of various of its body parts. But it does not settle how exactly its legs will move-that is left open, to be determined by the dog through its desires, impulses, and instincts.

Put more generically: there is nothing in the overall Anscombean picture we are considering that dictates that only physical matter can play the role of material. For instance, biological substances, tissues, organs, etc. can play the role of material, too. In principle, our background picture of things interacting with each other in accordance with their natures or dispositions leaves open whether determinism holds. It also leaves open whether there are any composite substances, substances that interact with other substances (composite or not) by using their constituent matter in certain ways-but if there be such substances, there must be indeterminism on the lower level. And, we now discover, it even leaves open that that there may

\footnotetext{
${ }^{23}$ Or, to be more precise, they would only be rivals if determinism were true on the physical level. Notice, as an aside, that this naturally gives us an answer to the so-called 'causal exclusion argument' that has been the subject of heated debates over the possibility of mental causation. In Jaegwon Kim's influential formulation, it reads "Given that every physical event that has a cause has a physical cause, how is a mental cause also possible?" (Kim 1998: p. 38). Very briefly, the answer is that, where initially a range of physical outcomes of a given physical cause are possible (i.e., under physical indeterminism), its ending up producing this particular physical outcome may be the result of non-physical factors. Hence there is only the threat of such causal exclusion if determinism is assumed: then, there is no range of potential physical outcomes left open for the non-physical factors to determine. For reasons of space, I cannot properly develop this response to Kim's causal exclusion challenge here; that would require translating it properly into the substance/power framework I am working with here, and attending to the rather excessive refinements of the problem that can be found in the corresponding literature (see Robb and Heil 2021: p. 6 for a good overview).

24 This gets us even closer to Steward's claim, mentioned before, that animals 'have' a body rather than 'being' one.
} 
be various levels of substances related in this manner, substances that make use of lower-level material. At all lower levels, indeterminism will then be required.

Thus we finally arrive at the idea of varieties of indeterminism: the biological requires physical indeterminism, animal self-movement requires biological indeterminism-and along these lines there appears to be room for the further claim that human agency in turn requires a form of 'animal indeterminism'. For if we characterize animal agency as situation-bound, in that it is fundamentally desire-driven and perception-guided, then "acting according to an idea" may be thought to require a suitable form of indeterminism not just on the physical and biological levels, but on this level of animal desires and drives as well. ${ }^{25}$-This is not to spell out such a position in any detail, but merely to highlight that the framework of varieties of indeterminism that I am suggesting here can provide for such a differentiation between animal and rational agency.

From this vantage point, interesting questions concerning the relations between the levels come into light. As I have just put it, one might think that higher-level substances are like 'layered cakes': in the case of an animal, for instance, we would have its constitutive physical matter, its living body, and the perceiving-desiring animal. I do not think this ultimately makes sense, but I will not argue for that claim here. An alternative conception would hold that the higher-level capacities 'transform' the lower levels: an animal is not a plant with perceptive and agentive faculties added on top; rather, what it is to have a living body in the first place is transformed by those faculties. ${ }^{26}$

This makes explicit a dimension to our Anscombean framework that I have not mentioned so far: we do not merely get varieties of indeterminism, but varieties of determinism as well. Each higher level, I said, requires indeterminism on all lower levels. It follows that there can only be one deterministic level; and that if any one level is deterministic, there cannot be any higher levels. But that leaves it open that there may still be lower levels-which must then of course be indeterministic.

In 'The Causation of Action', Anscombe considers the theoretical possibility of such a 'higher-level' determinism:

one might think that the descriptions of chemical or animal forms were not merely supervenient. ${ }^{27}$ But [one might still hold] that the existence and actions of all chemicals and animals that ever exist were determined-i.e. causally necessitated — from any previous point of time. (Anscombe 1983: p. 105; my addition)

\footnotetext{
25 See, for instance, Mulder (2018a, 2021a). The characterization of animals as 'situation-bound' derives from Sebastian Rödl's characterization of animal behavior as "situation-responsive behavior" (cf. Rödl 2012: p. 69-73).

26 See, e.g., Haase (2013) and Mulder (2021a). But see also Gobsch (2017) for an excellent discussion of the serious issues that such a 'transformative' picture faces.

27 'Supervenient descriptions' are, for Anscombe, descriptions that appear to concern different levels yet do not really do so. An example is talk of water waves interfering with each other: this is a supervenient description, in her sense, of the interaction between water masses. No incompatibilist conclusions concerning the water masses follows from such talk of water waves.
} 
Abstractly speaking, the thought here is that, while on the physical level many future possibilities are left open, those possibilities are brought down to exactly one by the (chemical or animal) factors that operate at the higher level.

Anscombe brings this theoretical possibility up because it bears on a 'fallacious argument' that was prevalent in her days: that microphysical indeterminism still translates into macrophysical determinism, because the indeterministic level is governed by statistical laws which effectively enforce conformity on the macro-level (see also C\&D: 146). ${ }^{28}$ Now, although she urges that there is no reason for endorsing this view (except for the 'deterministic itch' she complains about), Anscombe does not want to rule it out either:

[W]e just do not know whether, for example, the course taken by an animal is predetermined any time it runs about some area where the causal factors are constant. The appearance is otherwise; but that may be illusory-we ought to admit that we do not know." (Anscombe 1983: p. 106)

To be sure, this statement should be read as concerning the 'higher-level' form of predetermination I just introduced. Interestingly, even with regards to human agency, Anscombe keeps open the possibility of such a higher-level determinism-she speaks of the "possibility of holding deterministic views in relation to 'human' causality" (Anscombe 1983: p. 106) in just this sense.

It would be interesting to investigate what that could be: an autonomous level of 'human' causality that is, per laws of its own, deterministic. In particular, this raises a question for incompatibilists regarding free will: if free will is thought to be incompatible with determinism tout court, then what to say of such a situation? Of course, the usual incompatibilist argumentation depends precisely on the determining factors not being under our control ${ }^{29}$, so it is open to incompatibilists to argue that such a level-specific determinism, if coherent at all, does not pose a threat to freedom. But then it seems that the issue that is at stake in the free will debate is much better cast in terms of level-specific notions of (in)determinism than in terms of an apparently unitary notion of determinism. (Of course, as we saw, the existence of a level of human agency implies lower-level indeterminism, and insofar the classical rendering of the problem is apt, but simply too coarse-grained.)

\footnotetext{
${ }_{28}$ An anonymous referee pointed out to me that this 'fallacious argument' still finds currency in the contemporary free will debate. See, for instance, Pereboom (2007: 112f), who employs it in his argument against 'agent-causal libertarianism'. In C\&D, Anscombe attempts to rebut it by constructing her rather fanciful 'box analogy' (see C\&D: 146); see Müller (ms.) for an in-depth discussion showing the cogency and actual possibility of such an 'Anscombe-box'.

${ }^{29}$ This holds, for instance, for van Inwagen's Consequence Argument and Pereboom's Manipulation Argument, which I mentioned in $§ 1$ above.
} 


\section{Which levels? concluding afterthought}

I have given a rough sketch of a broadly Anscombean take on causality and determinism. It is primarily characterized by a reorientation: away from the supposed search for patterns in the ongoing train of events (be they necessary or universal or not) and towards an understanding of the ongoing train of events in terms of the concrete things (substances) around, with their capacities or powers. On this metaphysical picture, the laws of nature do not capture necessary or universal cooccurrences, but rather the way in which things respond to certain kinds of circumstances-responses which can in principle always be prevented or interfered with.

Now, we saw reason to distinguish, within this overall metaphysical picture, between certain levels, which can be characterized as follows: the higher-level things are such that their interactions with their environment make use of the possibilities provided by their constituent matter. Wherever we find apparent levels to be related in this way, we must conclude that the lower of the levels cannot be deterministic-for if it were, there would be nothing for the higher level to make use of. ${ }^{30}$

In my discussion of this framework on the basis of Anscombe's work, I have rather tendentiously spoken of quite specific levels: inanimate nature-life-animal self-movement-rational agency. But although traces of an interest in these specific levels can be found in Anscombe's writings (e.g., her frequent allusions to animal movement), I should stress that she does not endorse any specific list of levels (though she seems quite certain when it comes to the last one in my list). And neither was it my aim in this essay to develop or defend such a concrete proposal. ${ }^{31}$ Still, the very possibility of different levels along the sketched lines already makes quite a difference to our understanding of the classical free will debate, since it opens up the possibility of there being varieties of determinism and indeterminism, together with an analogous variety of incompatibility claims.

Most centrally, such a variegated picture may help us get away from the stark opposition between the mechanical causality of the physical level and human agency. If we allow ourselves to first attempt an understanding of life, and animal self-movement, as differing relevantly from the physical level, we may very well find ourselves in a position from which our power of 'acting according to an idea' makes much more sense. And more specifically, Anscombe's suggestion that there is the logical possibility of higher-level determinism at the level of human agency brings into focus that it is, in the end, a distraction to focus on some unitary notion of determinism in relation to human agency. What we really need to make progress

\footnotetext{
${ }^{30}$ Compatibilists will object here, of course: compatibilist senses of the idea of substances "making use of material" are easily cooked up, without any need for lower-level indeterminism. When we keep our substance/power scheme in place, however, it is clear that there is then a fundamental distinction between compatibilist 'substances' and 'powers', which make no difference to what goes on, and the substances and powers in which such compatibilist 'substances' and 'powers' are ultimately grounded, which genuinely do make differences. In Anscombe's terms (see fn. 27 above), all such substances are merely supervenient. Anyway, it has not been my aim to squarely confront the compatibilist in this essay; this is meant as a mere gesture towards such a confrontation.

31 But see Mulder (2021a).
} 
in the free will debate is, rather, a good understanding of what it means to determine something agentially, of what it is to "act according to an idea". And I think that this recommendation is fully in line with much of Anscombe's work in the relevant philosophical areas, in particular with her take on intentional agency as put forth in her monograph Intention (Anscombe 1957).

What stands in the way of taking seriously the broadly Anscombean picture I have tried to highlight here is, presumably, still the very same picture that Anscombe attempted to combat in her inaugural lecture $C \& D$ : a picture on which the only intelligible story on causality must rest upon some sort of (universal, or necessary) pattern among the elements of the ongoing chain of events. The varieties of indeterminism come into sight only if we reject that picture in favor of a picture on which interacting substances comprise our metaphysical bottom line. For then our bottom line already includes the possibility for such varieties of indeterminism: the mere idea of interacting substances covers both those that are and those that are not composed of 'material'.

Acknowledgements I am grateful to Dawa Ometto and Niels van Miltenburg, as well as to two anonymous referees, for their very helpful comments on earlier drafts of this article. And I gratefully acknowledge financial support from the Dutch National Science Foundation (NWO). VENI Grant scheme, Grant number 275-20-068.

Open Access This article is licensed under a Creative Commons Attribution 4.0 International License, which permits use, sharing, adaptation, distribution and reproduction in any medium or format, as long as you give appropriate credit to the original author(s) and the source, provide a link to the Creative Commons licence, and indicate if changes were made. The images or other third party material in this article are included in the article's Creative Commons licence, unless indicated otherwise in a credit line to the material. If material is not included in the article's Creative Commons licence and your intended use is not permitted by statutory regulation or exceeds the permitted use, you will need to obtain permission directly from the copyright holder. To view a copy of this licence, visit http://creativecommons.org/licen ses/by/4.0/.

\section{References}

Anscombe, G. E. M. (1971), 'Causality and Determination', in: Anscombe, G.E.M. (1981), Collected philosophical papers volume 2: metaphysics and the philosophy of mind. Oxford: Wiley-Blackwell.

Anscombe, G. E. M. (1983), 'The Causation of Action', in: Anscombe, G. E. M. (2005), Human Life, Action, and Ethics. Ed. by Mary Geach and Luke Gormally. Exeter: Imprint Academic, Ch. 9.

Anscombe, G. E. M. (1957). Intention. Basil Blackwell.

Armstrong, David M. (1997). A world of states of affairs. Cambridge University Press.

Cartwright, Nancy. (1983). How the laws of physics lie. Oxford University Press.

Cartwright, Nancy and John Pemberton. (2013), 'Aristotelian Powers: Without Them, What Would Modern Science Do?', in: Groff, Ruth and John Greco, eds. (2013), Powers and Capacities in Philosophy: The New Aristotelianism. New York: Routledge, Ch. 5

Elder, C. L. (2011). Familiar objects and their shadows. Cambridge University Press.

Gilbert, A. T., Petersen, B. W., Recuenco, S., et al. (2012). Evidence of rabies virus exposure among humans in the Peruvian Amazon. The American Journal of Tropical Medicine and Hygiene, 87(2), 206-15.

Gobsch, Wolfram. (2017). Der Mensch als Widerspruch und absolutes Wissen. In Andrea Kern \& Christian Kietzmann (Eds.), 2017, Selbstbewusstes Leben (pp. 120-172). Suhrkamp. 
Haase, Matthias. (2013). Life and Mind. In Thomas Khurana (Ed.), 2013, The freedom of life: hegelian perspectives (pp. 69-109). August Verlag.

Kim, J. (1998). Mind in a physical world. The MIT Press.

Lear, J. (1984). The disappearing “we.” Proceedings of the Aristotelian Society, Supplementary Volumes, $58,219-58$.

Mulder, Jesse M. (2021b). 'Absolute idealist powers', forthcoming in Australasian Journal of Philosophy. https://doi.org/10.1080/00048402.2021.1933556

Mulder, Jesse M. (2021c). 'The limits of reductionism: thought, life, and reality', in: Passon, Oliver \& Christoph Benzmüller (2021). Wider den Reduktionismus. Heidelberg: Springer Spektrum, Chapter 4.

Mulder, Jesse M. (2016). A vital challenge to materialism. Philosophy, 91(2), 153-82.

Mulder, Jesse M. (2018a). Why intentions? Ratio, 31(S1), 51-64.

Mulder, Jesse M. (2018b). 'The limits of humeanism.' European Journal for Philosophy of Science, 8, $671-87$.

Mulder, Jesse M. (2021). Varieties of power. Axiomathes, 31(1), 45-61.

Müller, Thomas (ms.), 'Let's Build an Anscombe Box', currently under review for this T.C.

Ometto, Dawa (ms.), 'Causality and Determination Revisited', currently under review for this T.C.

Pereboom, Derek (2007), 'Hard Incompatibilism', in J.M. Fischer, R. Kane, D. Pereboom, and M. Vargas (2007), Four Views on Free Will. Malden, MA: Blackwell, 85-125.

Pereboom, Derek. (2001). Living without free will. Cambridge University Press.

Pereboom, Derek. (2014). Free will, agency, and meaning in life. Oxford University Press.

Prior, Arthur N. (1962). Limited indeterminism. The Review of Metaphysics, 16(1), 55-61.

Robb, David and John Heil (2021), 'Mental Causation', The Stanford Encyclopedia of Philosophy (Spring 2021 Edition), E.N. Zalta (ed.). URL: https://plato.stanford.edu/archives/spr2021/entries/ mental-causation/

Rödl, Sebastian (2012), Categories of the Temporal. Translated by Sibylle Salewski. Cambridge, MA: Harvard University Press.

Steward, Helen. (2012). A metaphysics for freedom. Oxford University Press.

Steward, Helen. (2012). The metaphysical presuppositions of moral responsibility. The Journal of Ethics, 16: $241-71$.

Stroud, Barry. (2011). Engagement and metaphysical dissatisfaction. Oxford University Press.

van Inwagen, Peter. (1975). The incompatibility of free will and determinism. Philosophical Studies, 27, $185-99$.

van Inwagen, Peter. (1983). An essay on free will. Clarendon Press.

van Inwagen, Peter. (2000). Free will remains a mystery. Philosophical Perspectives, 14:1-20.

van Miltenburg, Niels, \& Ometto, Dawa. (2019). The libertarian predicament: a plea for action theory. Synthese, 196(1):161-78.

Whittle, Ann. (2003). Singularism. Proceedings of the Aristotelian Society, 103:371-80.

Publisher's Note Springer Nature remains neutral with regard to jurisdictional claims in published maps and institutional affiliations. 